\title{
BI-LATERAL MANIPULATOR FOR CONSTRUCTION WORKS
}

\author{
Shu TAKEDA, Hiroshi YOSHINADA \\ Kazuhiko OHTSUBO, Toshihisa NARUSE \\ Mechatronics Research Center, KOMATSU Ltd. \\ 1200 Manda, Hiratsuka-shi, Kanagawa, 254 JAPAN
}

\begin{abstract}
In this paper, we describe the bi-lateral manipulator for construction works, in which the large scale manipulartor with remote operation is needed.

Through the experiments, it was verified that the bi-lateral master-slave manipulator enables sensitive force control, smooth positioning and easy operating.

The availability for construction works has been verified by the applications for two works, troweling concrete in the tunnel, and erecting shield-segments.
\end{abstract}

\section{Introduction}

In recent years, many attempts to introduce robotics into construction works have been done, and also several kinds of fullautomatic robots have been developped.

However, their applicable sites are generally restricted and in most cases construction materials have to be newly designed suitable for robot tasks, and their systems are apt to be complex and expensive. And because of unexpected irregular cases which frequently happen in construction works, human operators have been always needed as a supervisor even in the full automatic robot systems.

Therefore we believe that the human operating robot system is a way of the automatization of the construction works.

Particularly the master-slave manipulator using tele-operation control is very suitable for the construction tasks because it can release the workers from dangerous and dirty work sites.

And if we want to accomplish the higher level tasks using the masterslave manipulator, it would need a some kind of force feedback control. Bi-lateral servo is well known as a typical force feedback control with master-slave manipulator.

Bi-lateral manipulators have been mainly used in the tele-opelation fields such as the maintenance of nuclear plants and subsea surveyors.

But most of them are not suitable for construction aspects, because of their small payload and small outreach.

In tis paper, we describe about the bi-rateral servo system suitable for large scale manipulator. 


\section{Features of the bi-lateral manipulator}

The bi-lateral manipulator we have developped and tested, consists of the control lever which is called the 'master'(See fig.1), and of the manipulator which is called the 'slave' (See Fig.2,3 and Table 1).

The slave has 7 degrees of freedom(D.O.F.) including a gripper. Every D.O.F. is actuated by oil hydraulics because the large payload is needed in the construction works.

Every D.O.F. is operated by remote control. 4 D.O.F., which are the azimth, the showlder, the elbow and the gripper are operated by the master lever, and the configuration of the master is similar to that of the slave and the size is $1 / 6$ of the slave. In these D.0.F., bilateral control is added and so the operator can feel the load acted on the slave.

The other 3 D.O.F. are controlled by one joystic lever with unilateral control then there is no force feedback.

Fig. 4 shows the control diagram of our bi-lateral control of each D.O.F., The slave has a potentiometer which detects the angle of the joint and 2 pressure sensors which detect bottom and head oil pressure of a cylinder. The cylinder is controlled by a servo valve.

The master has a D.C. servo motor which generates torque for force feedback according to the oil pressure of the cylinder, then the larger the load acting on the slave is, the larger the torque is.

The features of our bi-lateral control are below,

(1)Position and force feedback to the master

It is generally known that if the sensitive bi-lateral control is needed, the signal of the force which acts on the slave must be fedback to the master. But feedback loop is apt to be unstable with only force feedback in the hydraulic slave, because the hydraulic slave is not so responsive such as the electronic one.

So we added the feedback of the slave position to the master which increases stability of the feedback loop. Then we can realize sensitivity and stability of the bi-lateral control with the hydraulic slave.

(2) Cancel of viscosity and dead weight

The pressure sensor detects not only the load we want to sense but also the viscosity, dead weight and so on. Then the operator must sense these fedback force even though there is no load to the slave.

We canceled these force by the computer and could confirm the effectiveness of this cancel on sensitivity of the bi-lateral control.

(3) Variable feedback gain according to the velocity

The precise tasks are generally at low speed of the arm then the bi-lateral control is significant especially at low speed. On the other hand, it is not so needed to be sensitive at high speed handling. We changed the bi-lateral feedback gain according to the arm speed, high gain at low speed, and low gain at high speed.

(4)Small friction hardware 


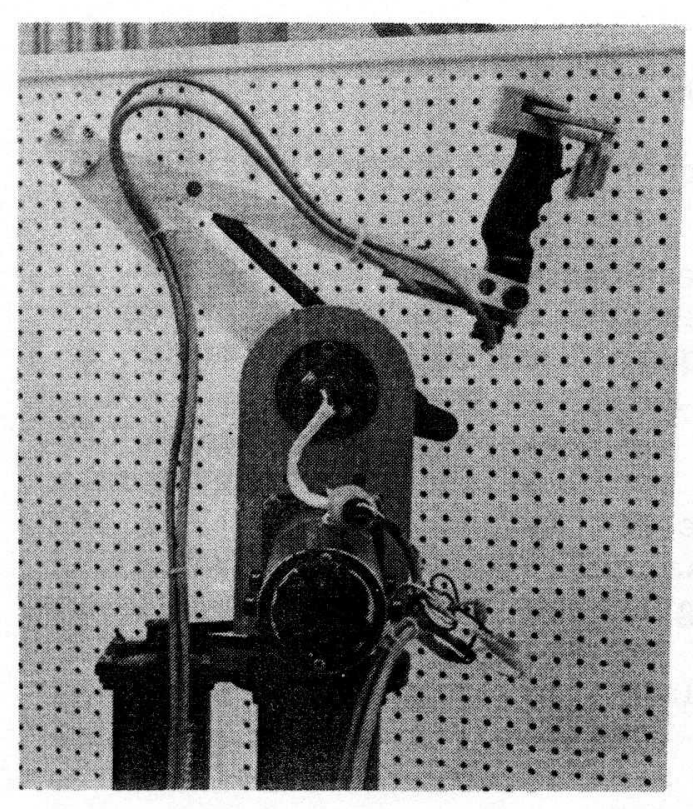

Fig. 1 the Master

\begin{tabular}{|c|c|}
\hline operation & master-slave \\
\hline $\begin{array}{l}\text { actuator } \\
\text { slave: } \\
\text { master: }\end{array}$ & $\begin{array}{l}\text { hydraulic } \\
\text { cylinder \& motor } \\
\text { DC servo motor }\end{array}$ \\
\hline power source & $200 \mathrm{v} 22 \mathrm{kw}$ \\
\hline payload & $200 \mathrm{~kg}$ \\
\hline $\begin{array}{c}\text { detectable } \\
\text { force }\end{array}$ & $\min .3 \mathrm{~kg}$ \\
\hline max speed & $1.2 \mathrm{~m} / \mathrm{sec}$ \\
\hline
\end{tabular}

Table 1 Specification

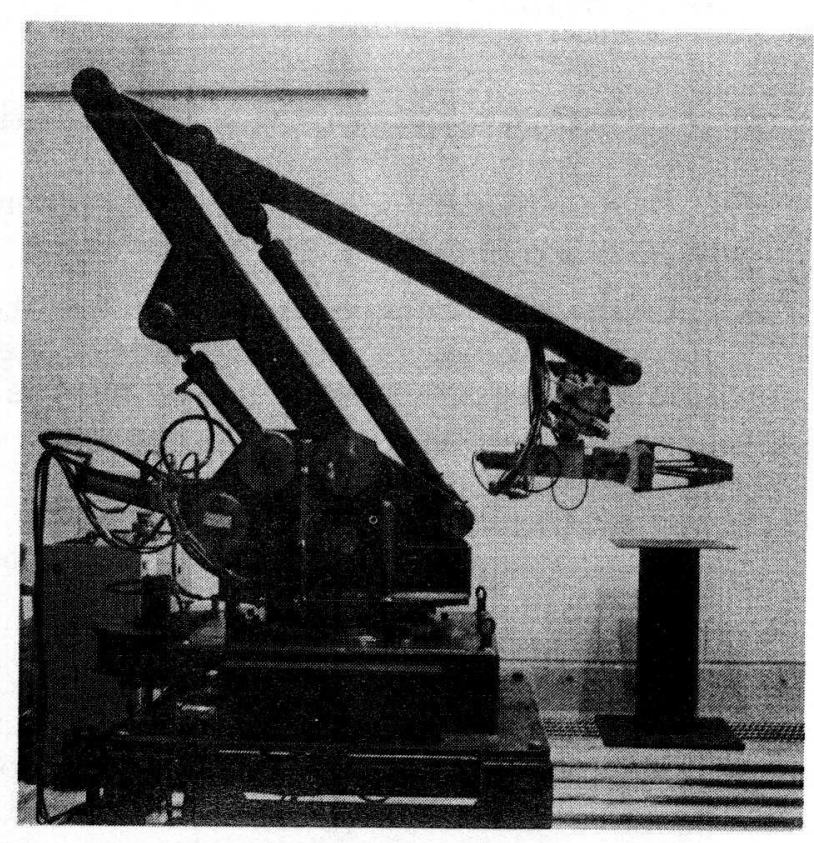

Fig. 2 the Slave

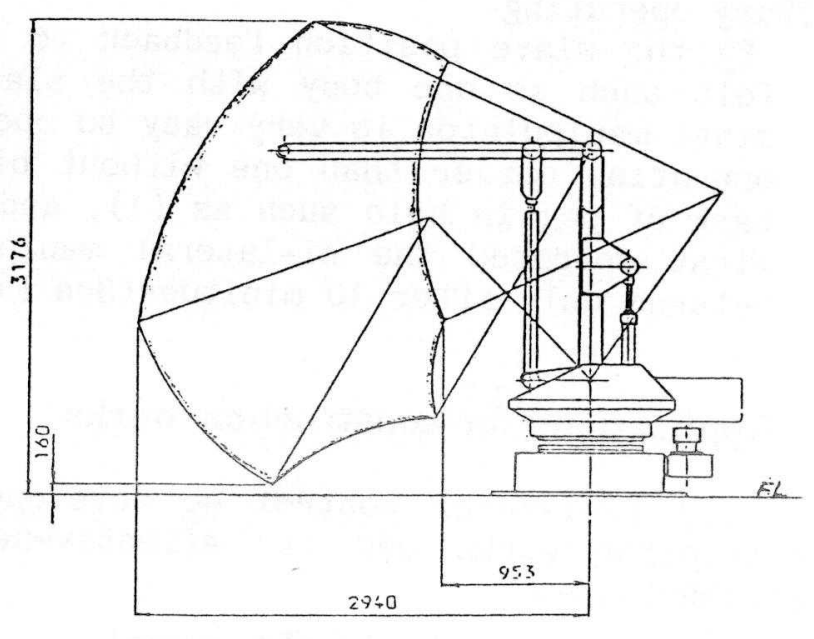

Fig.3 Configuration 
It was confirmed that the friction of the master and of the slave prevents from sensitive bi-lateral control. The friction was reduced by using the small friction cylinder of the slave and the small-ratio-reducer of the master D.C. motor which consists from timing belt.

\section{Proven Effectiveness of the Bi-Lateral Control}

The effectiveness of the bi-lateral control which was verified through the experiments is,

(1) Sensitive force control in the remote operation

With above mentioned methods, the operator can feel sensitively the load acting on the slave by the torque of the D.C. servo motor. Fig. 5 shows the relation between the force of the master and of the slave, and that the force of the slave is accurately reproducted in the master. And it was verified that the operator can feel $3 \mathrm{~kg}$ load which is $3 / 200$ of the payload.

We tested this effectiveness in a task of insertion of peg in hole(See FIg. 6). It shows that by using the bi-lateral manipulator the operator can insert a peg in hole smoothly without excessive load, and that the bi-lateral manipulator is very suitable for precise tasks in which force control is needed.

We have already applied the bi-lateral manipulator which has 1,500 $\mathrm{kg}$ payload, for glinding in our cast plants.

(2) Smooth positioning

The operator can feel the inertia of the slave, then can operate smoothly specially in rough and precise positioning.

(3) Easy operating

By the slave position feedback to the master, the master can be felt such as one body with the slave. So the bi-lateral masterslave manipulator is very easy to operate and evryone can learn the operation easier than one without bi-lateral control. We tested a task of peg in hole such as (1), and confirmed that a beginner who first operated the bi-lateral manipulator could operate so as a veteran only after 10 minitues(See Fig. 7).

\section{Applications for construction works}

The bi-lateral control we developped have been applied for two construction works and its effectiveness has been verified in the experiments.

(1)Troweling concrete in the Tunnel

troweling concrete on the rock in the tunnel reduces material loss of rebounding and the dust, then is for cost and safety, superior to conventional spraying concrete.

For troweling concrete in the large tunnel and for following any shape of profile, the master-slave manipulator is very suitable. 


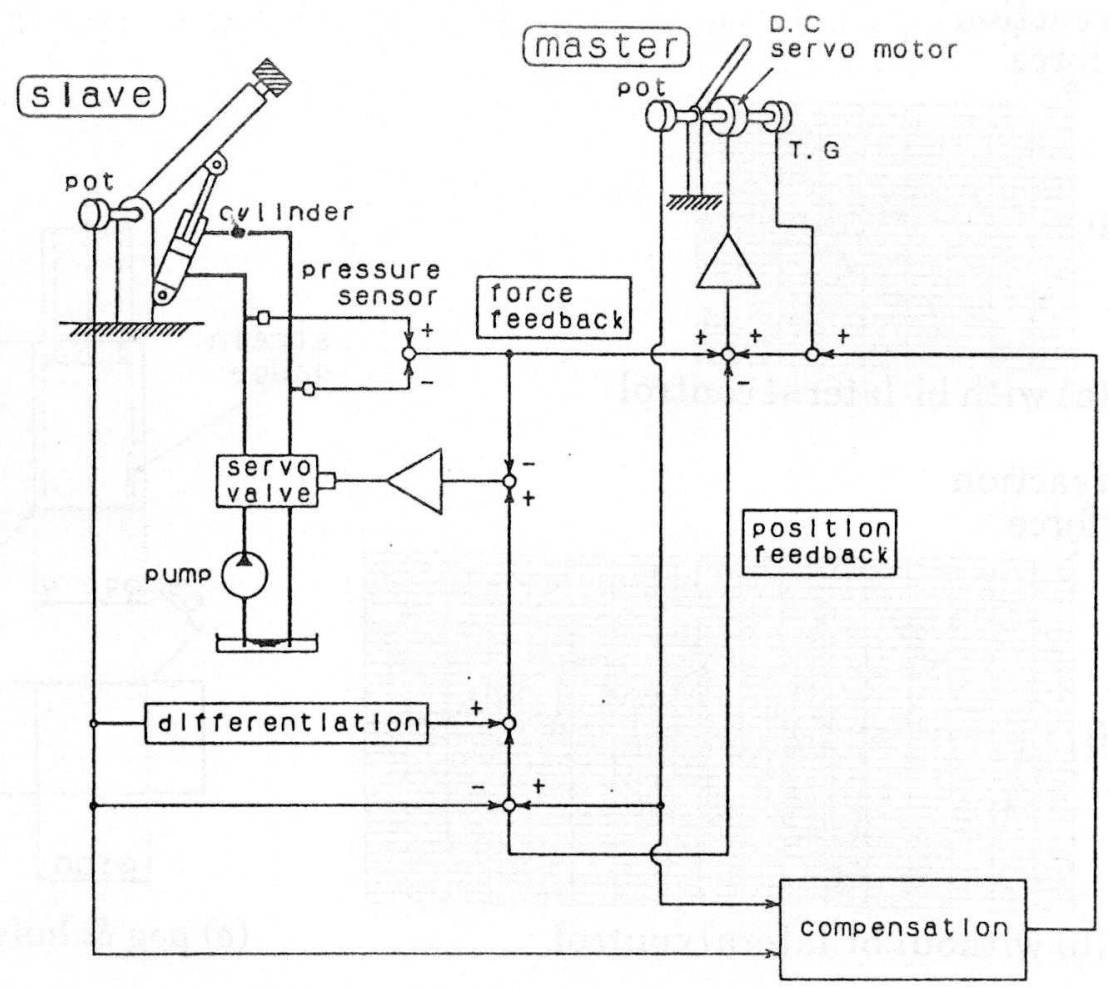

Fig. 4 Control Diagram

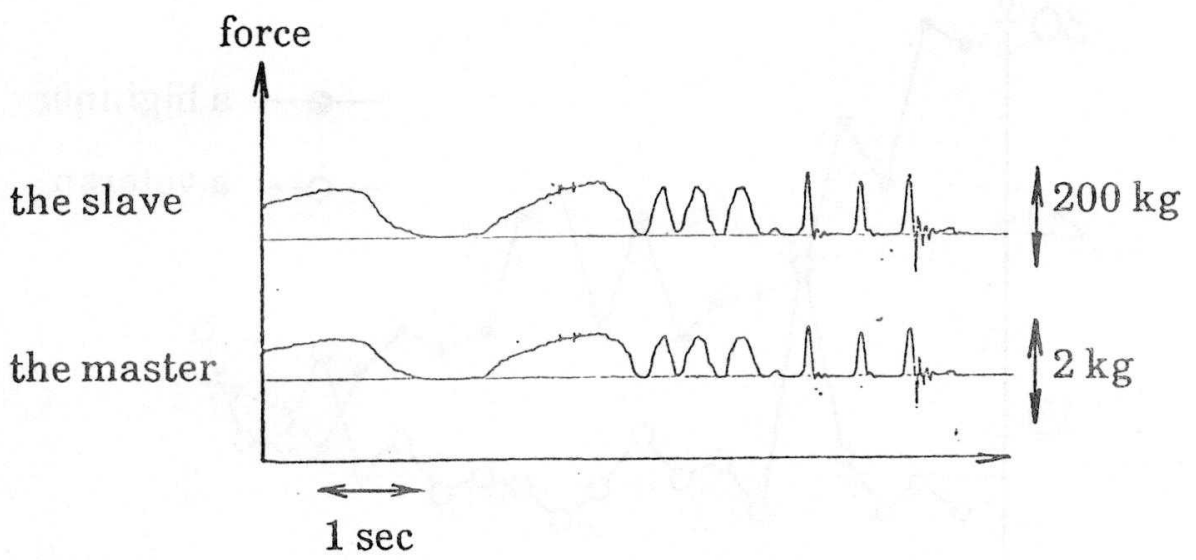

Fig. 5 the Force of the Master and the Slave 


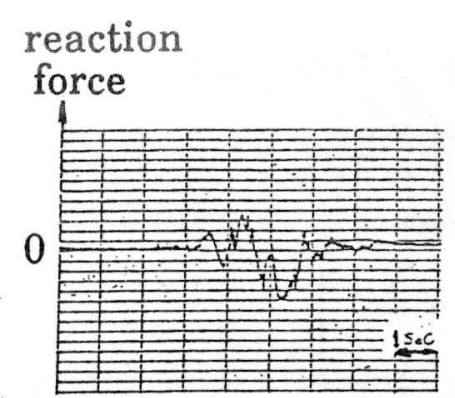

(a) with bi-lateral control

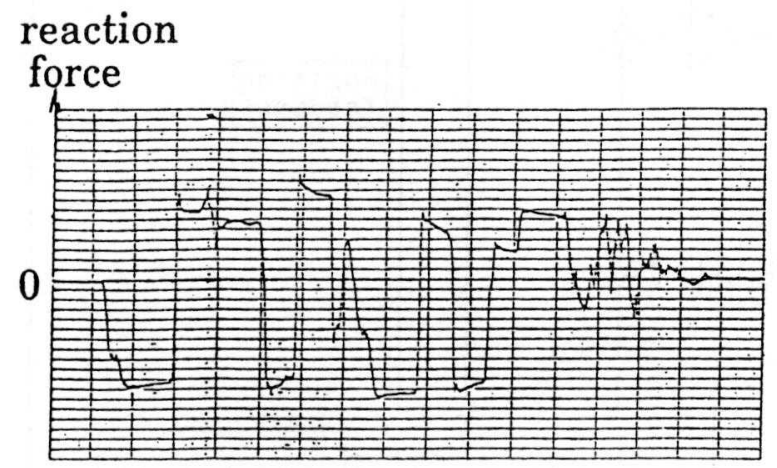

(b) without bi-lateral control

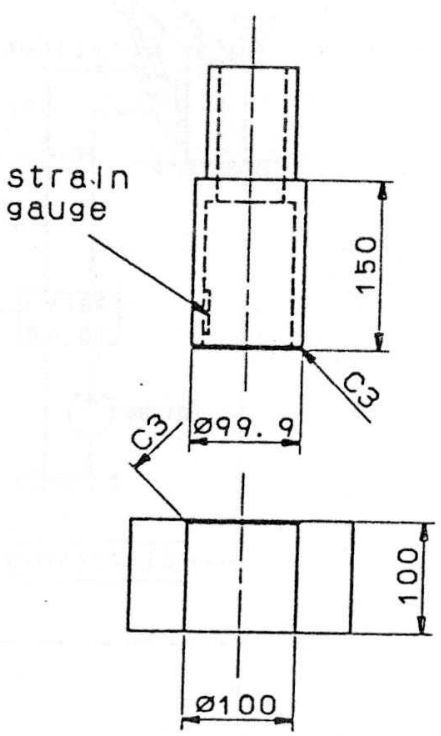

(c) peg \& hole

Fig. 6 The Test of Insertion of a Peg in Hole

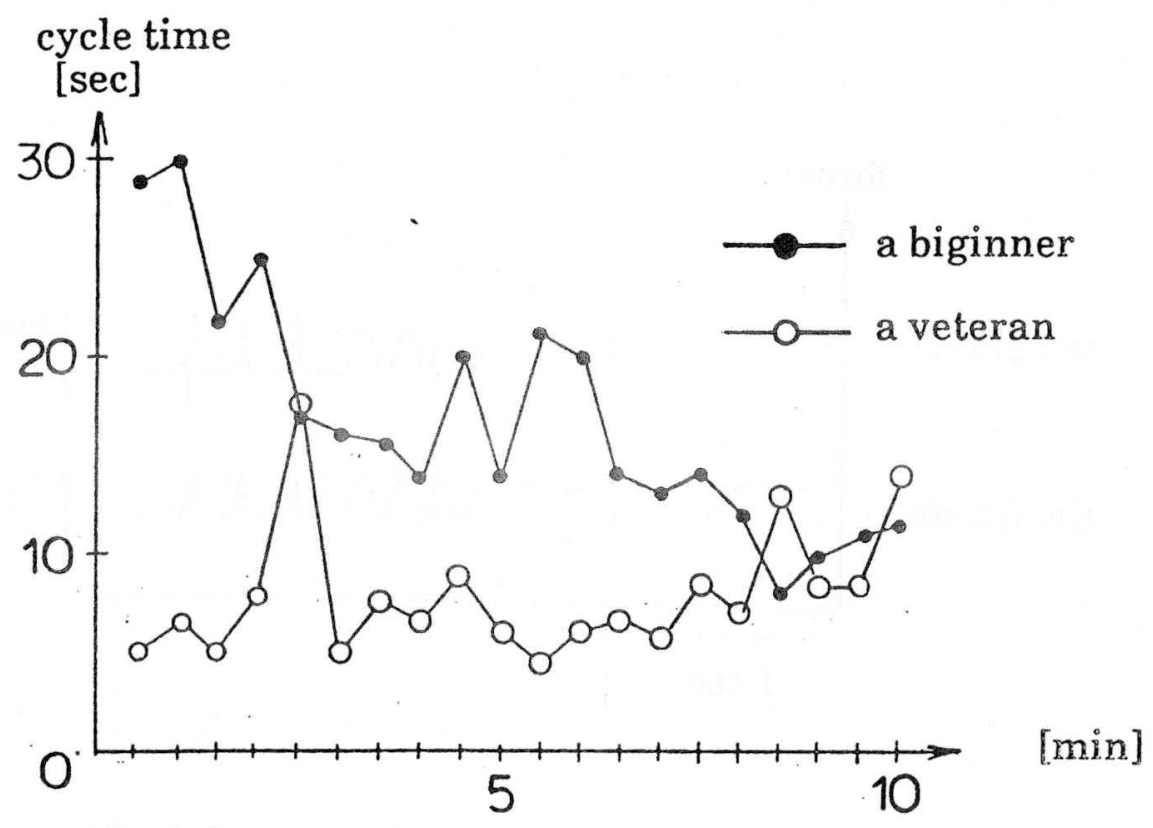

Fig. 7 Learning Curve 
Specially bi-lateral control is very needed because it is necessary to control to push with constant force.

We are now testing the bi-lateral manipulator which has 5 D.O.F. and a trowel as an end effector(See Fig. 8). It was confirmed by the experiments that concrete could be very thinly and equally troweled.

(2)Erecting shield-segments

We have applied the bi-lateral control for erecting shieldsegments(See Fig. 9). This erection manipulator has 6 D.0.F.. 3 D.O.F. are remote operated by the master and in which the bilateral control is applied, and the other 3 D.O.F. which are pitch, yaw and roll, are controlled with pressure feedback by which a segment can follow automatically the attitude of the segments which are already assembled. By adding bi-lateral control, below is confirmed.

(a) this manipulator is adaptive to any kind of segments and to the scale error of segments because of the visual feedback of the operator. For the same reason the sensor systems become simpler than that of full-automatic erection robots.

(b) the operator can feel the force to contact with the segments already assembled, and can assemble without no damage on the edge and the seal.

The results of the experiments in these two applications will be reported in the near future.

\section{Conclusion}

In the construction works, semi-automatic system with human operators as supervisors is very simple and very applicable. Particularly the master-slave manipulator with bi-lateral control is useful for the remote operating in the higher level tasks.

We developped the bi-lateral control suitable for large scale manipulator actuated by oil hydraulics. Through the experiments of the manipulator added the bi-lateral control, it was verified that bilateral control enables sensitive force control, smooth positioning and easy operating.

We applied this bi-lateral control for two construction works, troweled concrete in the tunnel and erecting shield-segments, and its effectiveness has been verified.

We believe that the bi-lateral control is available for many other kinds of the construction works, and are going to search for the application sites.

\section{Reference}

1)W.R.Ferrell and T.B.Sheridan, "Supervisory Control of Remote Manipulation", IEEE Spectrum, Oct. 1967, pp.81-88

2)M.Ejiri, "Characteristics of the Bi-lateral Servo Mechanism", J. JSME, vol. 31, no.230, 1484/1491(1965) 


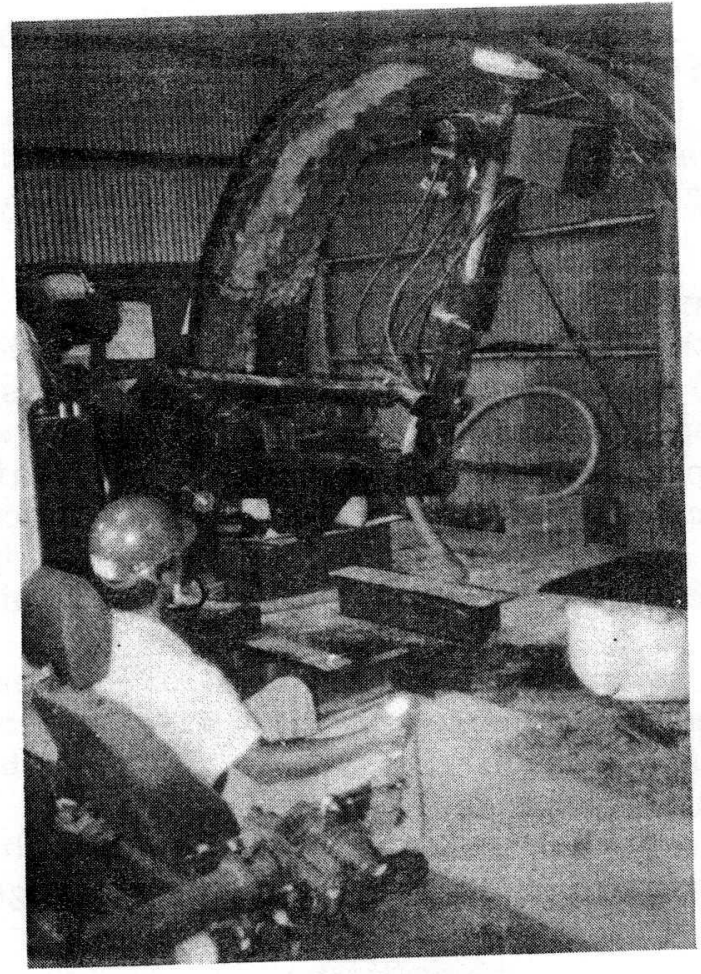

Fig. 8 Application (1)

(Troweling Concrete in the Tunnel)

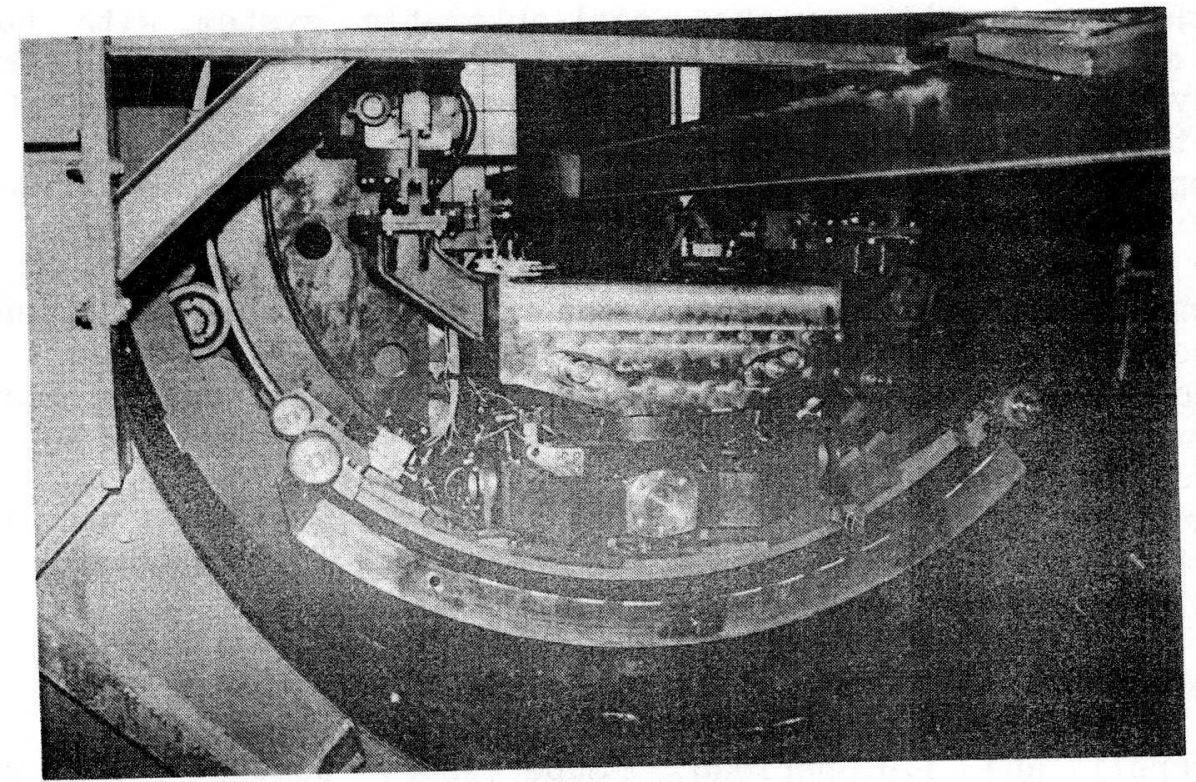

Fig. 9 Application..(2)

(Erecting Shield-Segment) 